Original research article

Section: Nutritional Research

\title{
Continuous Consumption of Reused Palm Oil Induced Hepatic Injury, Depletion of Glutathione Stores, and Modulation of Cytochrome P450 Profiles in Mice
}

\author{
Waranya Chatuphonprasert ${ }^{1}$, Yollada Sriset ${ }^{2}$, Kanokwan Jarukamjorn ${ }^{2, *}$ \\ ${ }^{1}$ Faculty of Medicine, Mahasarakham University, Mahasarakham, 44000 Thailand \\ ${ }^{2}$ Research Group for Pharmaceutical Activities of Natural Products using Pharmaceutical Biotechnology, Faculty \\ of Pharmaceutical Sciences, Khon Kaen University, Mitrapaab Road, Khon Kaen, 40002,Thailand
}

Key words: cytochrome P450, glutathione stores, oxidative stress, histology, liver, reused palm oil

Cooking oil deteriorates with repeated thermal exposure, resulting in appearance change and formation of oxygen radicals. Consumption of the deteriorated oil causes oxidative stress related to lipid metabolism. This study evaluated the effects of palm (Elaeis guineensis Jacq.) oil on hepatic histology, redox status, and cytochrome P450 (CYP) profiles. Adult female mice were orally given purified water (control), fresh, or reused palm oil $(4.5 \mathrm{~g} / \mathrm{kg} /$ day) daily for 16,24 , and 36 weeks. The livers were then collected for histological examination and for the evaluation of the redox system and CYP expression profiles. Treatment with fresh oil for 36 weeks resulted in some pyknosis and karyorrhexis in hepatic tissues, while reused oil resulted in more injuries to the nuclei with hepatic fat accumulation from week 24 onwards. Depletion in reduced glutathione (GSH) stores, with a significant decrease in the GSH/GSSG ratio, was observed with the reused oil but not with the fresh oil. The expression profiles of drug-metabolizing CYPs were significantly modulated; Cyp2c29, Cyp3a11, and Cyp3a13 were suppressed by both fresh and reused oil, while only the reused oil elevated Cyp2el. The expression of Cyp4al0 and Cyp4al4, the key enzymes in lipid metabolism, were expectedly up-regulated by both. These findings suggest reused oil has a deleterious effect on hepatic ultrastructure, induces an imbalance of redox state, and causes Cyp2el activation-associated oxidative stress. It is therefore recommended that fresh rather than reused palm oil be used for cooking, and large-scale or long-term consumption be avoided to reduce the risk of liver damage and drug-interactions.

\section{INTRODUCTION}

Palm (Elaeis guineensis Jacq.) oil is a frequently used cooking oil for frying, and is normally reused for economic reasons [Carter et al., 2007; Ku et al., 2014]. Exposure to high temperatures during the frying process causes deterioration of oil physical and chemical properties [Latha \& Nasirullah, 2014]. Oxidative physical changes include an increase in viscosity and the development of a brown color and rancid smell [Bordin et al., 2013], while chemical changes result in the production of hazardous by-products such as peroxides [Leong et al., 2012], and trans-fat [Kemény et al., 2001]. Peroxides are hazardous because they can overwhelm an organism's oxidant-antioxidant system by the excessive formation of prooxidants [Coyle et al., 2006], while trans-fats have been shown to damage cell membranes and impede the activity of major lipid metabolizing enzymes, leading to oxidative stress [Totani \& Ojiri, 2007]. Oxidative stress has been identified as a risk factor for metabolic diseases such as insulin resistance [Chao et al., 2007], hypertension [Jaarin et al., 2011], and atherosclerosis [Ng et al., 2014]. Also, a previous study with male ICR mice receiving a regular diet supplemented with $25 \%$ reused oil for 12 weeks showed that the test animals developed swelling and necrosis of their hepatic cells [Hashem \& Salama, 2012].

Cytochrome P450 (CYP) is a superfamily of mono-oxygenase enzymes abundant in the liver, and plays a pivotal role in the metabolism of endogenous substances and detoxification of foreign compounds [Nebert et al., 2013]. Consumption of reused oil is associated with the induction of these CYP enzymes and also antioxidant enzymes in rats. Levels of CYP3A, CYP4A, and catalase proteins were all increased in rats fed with oxidized soybean oil for 6 weeks [Huang et al., 2009], while rats fed a regular diet plus $20 \%$ reused soybean oil showed up-regulated expression of Cyp4al, Cyp4a2, and Cyp4a3 mRNAs [Chao et al., 2001]. Finally, an increase in free radical levels was believed to be responsible for reduced NO levels and increased blood pressure in rats fed reused palm and soybean oils for 24 weeks [Jaarin et al., 2011]. Therefore, it is of interest to evaluate how reused palm oil influences hepatic histology, redox status, and expression of CYP enzymes, including xenobiotic metabolizing isoforms, i.e. Cypla2, Cyp2c9, Cyp2el, Cyp3a11, and Cyp3a13, and lipid metabolizing isoforms, i.e. Cyp4a10 and Cyp4a14.

\footnotetext{
* Corresponding Author: Tel/Fax: 043-202379; 043-202305;

E-mail: kanok_ja@kku.ac.th (Prof. K. Jarukamjorn) 


\section{MATERIALS AND METHODS}

\section{Chemicals and reagents}

The lipid profiles of fresh palm oil used in this study, Morakot $^{\circledR}$ (total fat content 94.96 g/100 g; Samut Prakan, Thailand), and reused palm oil (total fat content $94.89 \mathrm{~g} / 100 \mathrm{~g}$ ) collected from a deep-frying food (fish, squid, chicken, pork, meat, and seasoning sausages) stall in Khon Kaen (Thailand) in September 2014, were certified by the Food and Nutrition Laboratory, Institute of Nutrition, Mahidol University, Thailand (Table 1).

Bovine serum albumin (BSA), glutathione reductase, reduced glutathione (GSH), oxidized glutathione (GSSG), malondialdehyde (MDA), 4-vinyl pyridine (4-VP), and thiobarbituric acid were supplied by Sigma-Aldrich Chemicals (St. Louis, Missouri, USA). ReverTraAce ${ }^{\circledR}$ was a product of Toyobo Co., Ltd (Osaka, Japan). Taq DNA polymerase, RNase inhibitors, and random primers were obtained from Invitrogen Life Technologies (Carlsbad, CA, USA). SYBR ${ }^{\circledR}$ Green I was purchased from Cambrex Bio Science Rockland, Inc. (Rockland, ME, USA). Forward and reverse primers of Cyp1a2, Cyp2c29, Cyp2e1, Cyp3a11, Cyp3a13, Cyp4a10, Cyp4a14, and Gapdh genes were synthesized by Bio Basic, Inc. (Markham Ontario, Canada). The primers of each gene are shown in Table 2. Eosin Y and Mayer's hematoxylin (H\&E) was obtained from Bio Optica (Milano, Italy). All other laboratory chemicals were of the highest available purity from commercial suppliers.

\section{Animal treatment}

Seven-week-old female ICR mice were supplied by the National Laboratory Animal Center, Mahidol University, and housed in the Animal Unit of Faculty of Pharmaceutical Sciences, Khon Kaen University (Thailand) under the supervision of a licensed laboratory veterinarian. The animal handling and research protocols were approved by the Animal Ethics Committee for Use and Care of Animals, Khon Kaen University (Approval No. ACUC-KKU 30/2557) in accordance with the Declaration of Helsinki and/or with the Guide for the Care and Use of Laboratory Animals as adopted and promulgated by the United States National Insti-
TABLE 1. Fatty acid composition $(\mathrm{g} / 100 \mathrm{~g}$ total fatty acid) of the fresh and reused palm oil*.

\begin{tabular}{|c|c|c|c|}
\hline Fatty acid** & & Fresh & Reused \\
\hline Caprylic acid & C 8:0 & ND & 0.02 \\
\hline Capric acid & C $10: 0$ & ND & 0.02 \\
\hline Lauric acid & C 12:0 & 0.24 & 0.37 \\
\hline Myristic acid & C 14:0 & 0.87 & 1.28 \\
\hline Palmitic acid & C $16: 0$ & 36.83 & 35.30 \\
\hline Palmitoleic acid & C $16: 1$ & ND & 1.01 \\
\hline Stearic acid & C $18: 0$ & 4.22 & 5.45 \\
\hline Elaidic & C $18: 1$ trans- 9 & ND & 0.08 \\
\hline Oleic acid & C $18: 1 \mathrm{n} 9$ cis & 47.10 & 43.94 \\
\hline Linoleic acid & C $18: 2 \mathrm{c} 9 \mathrm{t} 12$ & ND & 0.16 \\
\hline Linoleic acid & C $18: 2$ t9 c12 & ND & 0.15 \\
\hline Linoleic acid & $\begin{array}{c}\text { C } 18: 2 \mathrm{n} 6 \text { cis } \\
\text { (c9 } \mathrm{cl} 12)\end{array}$ & 10.14 & 10.54 \\
\hline Linoleic acid & C $18: 3 \mathrm{n} 3$ & 0.60 & 0.06 \\
\hline Eicosenoic acid & C 20:1 & ND & 0.55 \\
\hline Eicosapentaenoic acid & C $20: 5 \mathrm{n} 3$ & ND & 0.26 \\
\hline Docosadienoic acid & C $22: 2$ & ND & 0.20 \\
\hline Docosahexaenoic acid & C $22: 6, n-3$ & ND & 0.63 \\
\hline Sum of trans fatty acids ${ }^{* * *}$ & & ND & 0.38 \\
\hline
\end{tabular}

*certified by the Food and Nutrition Laboratory, Institute of Nutrition, Mahidol University, Thailand; ND, not detected. ${ }^{* *}$ AOAC [2016a]. ***AOAC [2016b].

tutes of Health. All mice were housed on wood chip bedding in polysulfone cages with water and commercial regular diet (SmartHeart ${ }^{\circledR}$ from Perfect Companion Pet Care Company, Bangkok, Thailand) supplied ad libitum with a 12-h dark/ light cycle under a controlled temperature $\left(23 \pm 2{ }^{\circ} \mathrm{C}\right)$ and humidity ( $45 \pm 2 \%)$, and acclimated for a week before dosing, and random division into 3 groups. Each group $(n=15$ each)

TABLE 2. Forward and reward primer sequences.

\begin{tabular}{l|c|c|c|c|c}
\hline Genes & Accession No. & Forward primers $\left(5^{\prime} \rightarrow 3^{\prime}\right)$ & Reverse primers $\left(5^{\prime} \rightarrow 3^{\prime}\right)$ & $\begin{array}{c}\text { Annealing } \\
\text { temperature } \\
\left({ }^{\circ} \mathrm{C}\right)\end{array}$ & $\begin{array}{c}\text { Product } \\
\text { size } \\
(\mathrm{bp})\end{array}$ \\
\hline Cypla2 & NM_009993.3 & CGT CAG CAA GCT TCA GAA GG & ACG ATG TTC AGC ATC TCC TCG & 57.0 & 144 \\
Cyp2c29 & NM_007815 & ATC TGG TCG TGT TCC TAG CG & AGT AGG CTT TGA GCC CAA ATA C & 50.0 & 218 \\
Cyp2el & NM_021282.2 & TCC CTA AGT ATC CTC CGT GA & GTA ATC GAA GCG TTT GTT GA & 50.0 & 529 \\
Cyp3al1 & NM_007818.3 & TTT GGT AAA GTA CTT GAG GCA GA & CTG GGT TGT TGA GGG AAT C & 64.0 & 134 \\
Cyp3al3 & NM_007819.4 & TGT GCT GGC TAT CAC AGA TCC & AAA TAC CCA CTG GAC CAA AGC & 55.0 & 101 \\
Cyp4al0 & NM_010011.3 & GTG CTG AGG TGG ACA CAT TCA T & TGT GGC CAG AGC ATA GAA GAT C & 54.2 & 83 \\
Cyp4al4 & NM_007822.2 & TGC AGA AGG CCA GGA AGA AG & CAC ATG GTG GTG TAG GGC AT & 60.5 & 286 \\
Gapdh & NM_008084.3 & CCT CGT CCC GTA GAC AAA ATG & TGA AGG GGT CGT TGA TGG C & 57.4 & 152 \\
\hline
\end{tabular}


was orally given the fresh or reused palm oil $(4.5 \mathrm{~g} / \mathrm{kg} / \mathrm{day})$ daily for 16, 24, and 36 weeks. The control group $(n=5)$ was given purified water $(0.2 \mathrm{~mL} / \mathrm{mouse} /$ day $)$ for the same time periods. Mice were sacrificed $24 \mathrm{~h}$ after the last treatment and their livers were immediately excised; a portion was fixed for histological examination and the remains were stored at $-80^{\circ} \mathrm{C}$ for further analysis.

\section{Liver histological examination}

Following excision, small pieces of liver tissue were washed immediately in phosphate buffered saline, fixed overnight in $10 \%$ neutral-buffered-formalin, dehydrated using gradient ethanol concentration, and embedded in paraffin. The paraffin embedded tissues were cut into $5 \mathrm{~mm}$ sections using a Microm HM315 machine (Thermo Scientific, Walldorf, Germany) and fixed on microslides. The microslides were stained with hematoxylin and eosin (H\&E) and examined at $400 \times$ magnification on an Axiostar plus microscope (Carl Ziess, Oberkochen, Germany) coupled with EOS SDS digital camera and EOS software (Canon ${ }^{\circledR}$, Tokyo, Japan) [Jearapong et al., 2015].

\section{Determination of hepatic glutathione contents}

Liver homogenate was deproteinized with $5 \%(\mathrm{w} / \mathrm{v}) 5$-sulfosalicylic acid before centrifugation at $10,000 \times g$ at $4^{\circ} \mathrm{C}$ for $10 \mathrm{~min}$. The supernatant was mixed with a freshly prepared reaction mixture containing $95 \mathrm{mM}$ potassium phosphate buffer ( $\mathrm{pH} 7.0), 0.95 \mathrm{mM}$ ethylenediamine tetraacetic acid, $0.04 \mathrm{mg} / \mathrm{mL}$ 5,5'-dithiobis(2-nitrobenzoic acid), and 0.12 units $/ \mathrm{mL}$ glutathione reductase. The reaction was started by adding $0.04 \mathrm{mg} / \mathrm{mL}$ NADPH, and absorbance at a wavelength of $405 \mathrm{~nm}$ was immediately measured every $60 \mathrm{~s}$ for $5 \mathrm{~min}$. Total glutathione content was determined by comparing the absorbance of sample with that of GSH standard. The GSH (reduced form) content was calculated by subtracting the GSSG (oxidized form) content from the total glutathione content. To determine the GSSG content, 4-VP was added to the supernatant, and the sample was incubated for $60 \mathrm{~min}$ at room temperature. Other steps were done as described for the assay of the total glutathione content. The contents of total glutathione, GSH, and GSSG were expressed in units of nmol per mg of protein [Akerboom \& Sies, 1981]. Protein content was quantified using the method of Bradford, with the protein-dye complex measured at a wavelength of $595 \mathrm{~nm}$ using BSA as a standard [Bradford, 1976].

\section{Determination of thiobarbituric acid reactive substances (TBARS)}

Lipid peroxidation was determined by measuring the formation of TBARS [Wasowicz et al., 1993]. In brief, a $50 \mu \mathrm{L}$ aliquot of liver homogenate was incubated at $37^{\circ} \mathrm{C}$ for $1 \mathrm{~h}$, and then a mixture $(0.5 \mathrm{~mL})$ of an equal volume of $10 \%(\mathrm{w} / \mathrm{v})$ trichloroacetic acid (TCA) and $0.8 \%(\mathrm{w} / \mathrm{v})$ 2-thiobarbituric acid (TBA, in $25 \%$ acetic acid) was added. The reaction mixture was boiled at $100^{\circ} \mathrm{C}$ for 15 min before immediately cooling in an ice bath. The reaction was stopped by the addition of $10 \%(\mathrm{w} / \mathrm{v}) \mathrm{TCA}(0.5 \mathrm{~mL})$ and the reaction mixture was centrifuged (Sartorius Model 2-16K, Göttingen, Germany) at $1,200 \times g$ at room temperature for $5 \mathrm{~min}$. The supernatant was measured by a spectrofluorometer at an excitation wavelength of $520 \mathrm{~nm}$ and an emission wavelength of $590 \mathrm{~nm}$. MDA was used as a standard in concentration ranging from 0.5 to 4 nmol. Results were expressed as nmol MDA per mg of protein. The protein content of the liver homogenate was determined using the method of Bradford [Bradford, 1976].

\section{Assessment of RT-qPCR}

Total RNA was reverse transcribed using ReverTraAce ${ }^{\circledR}$ under the conditions recommended by the supplier (Toyobo Co. Ltd., Osaka, Japan) at $25^{\circ} \mathrm{C}$ for $10 \mathrm{~min}, 42^{\circ} \mathrm{C}$ for $60 \mathrm{~min}$, and $95^{\circ} \mathrm{C}$ for $5 \mathrm{~min}$ on a GeneAmp PCR system 2720 ThermalCycler (Applied Biosystem, Singapore). The CYP mRNAs were quantified by qPCR using SYBR ${ }^{\circledR}$ Green I with specific forward and reverse primers which were designed by PrimerBLAST (https://www.ncbi.nlm.nih.gov/tools/primer-blast/) and synthesized by Bio Basic Inc. (Markham ON, Canada) (Table 2). The reaction of qPCR was performed in a final volume of $20 \mu \mathrm{L}$ containing $20 \mathrm{ng}$ of cDNA, Thunderbird ${ }^{\circledR}$ SYBR $^{\circledR}$ qPCR Mix (Toyobo Co. Ltd., Osaka, Japan), and 5 pmol of each primer. The following thermal program was applied: a single cycle of DNA polymerase activation for $10 \mathrm{~min}$ at $95^{\circ} \mathrm{C}$ followed by $40-50$ amplification cycles of $20 \mathrm{~s}$ at $95^{\circ} \mathrm{C}$ (denaturing step) and $20 \mathrm{~s}$ at annealing step, and $30 \mathrm{~s}$ at $72^{\circ} \mathrm{C}$ for extension step. Subsequently, melting temperature analysis of the amplification products was performed by gradually increasing the temperature from 60 to $95^{\circ} \mathrm{C}\left( \pm 0.5^{\circ} \mathrm{C} / 20 \mathrm{~s}\right)$. The fluorescent reporter signal was normalized against the internal reference dye (ROX) signal and the threshold limit setting was performed in automatic mode, according to the iCycler Thermal Cycler (Hercules, CA, USA) and Biorad-iQ5 software (Hercules, CA, USA). The CYP gene mRNA levels were normalized to a reference gene, Gapdh [Jearapong et al., 2015].

\section{Statistical analysis}

A power analysis was performed with $G^{*}$ Power version 3.1 [Faul et al., 2007] to determine what sample size would be needed to detect a significant difference in TBARS and glutathione contents, and relative CYP expression. The sample size was calculated using the power procedure for one-way analysis of variance (ANOVA), considering $\alpha$ probability of 0.05 with a power of 0.80 . The power analysis determined a sample size of 5 mice per group. Statistical analyses were performed using one-way ANOVA followed by the Tukey post hoc test (SPSS version 17.0, SPSS Inc., Chicago, IL, USA). All data are expressed as mean $\pm \mathrm{SD}(\mathrm{n}=5)$. A difference with $P<0.05$ was considered significant.

\section{RESULTS AND DISCUSSION}

\section{Reused oil drew hepatic injury in the mice}

Palm oil provides nearly $30 \%$ of the world edible vegetable oil, and is regularly used for frying food in Southeast Asia [Carter et al., 2007]. Palm oil becomes thermally oxidized after several rounds of heating to $150^{\circ} \mathrm{C}$, generating oxygen-derived free radicals and hydroxylated products that are harmful to tissues [Frankel, 2014]. Wistar rats fed with either fresh or oxidized palm oil for 18 weeks had higher serum lev- 
els of alkaline phosphatase (ALP), alanine aminotransferase (ALT), and aspartate aminotransferase (AST) [Owu et al., 1998]. Serum total cholesterol levels of rats fed hydrogenated oil containing palm oil for 4 weeks was significantly increased compared to controls too [Amini et al., 2017].

In this study, consumption of fresh or reused palm oil for 36 weeks did not alter mouse weight profiles between groups (data not shown), but did affect hepatocellular structures. H\&E stained micrographs of hepatic tissues are shown in Figure 1. The hepatic tissues of mice that consumed fresh palm oil exhibited normal histology at week 24, with limited pyknosis and karyorrhexis of hepatocyte nuclei later observed at 36 weeks. The hepatic tissues of mice that consumed reused palm oil showed much more damage and extensive pyknosis, this being detectable at week 24. At week 36, pyknosis had developed into karyorrhexis and the hepatocytes had become swollen with extensive vacuolation and fat droplet accumulation. Hepatocyte degeneration, damage to sinusoid structure, and loss of hepatic architectural integrity were also observed at week 36 in the mice fed reused palm oil.

Ingestion of heated and oxygenated corn oil has been shown to induce liver injury in rats by cell membrane damage from active oxygen radicals contained in the heated and also oxygenated oil [Shibayama, 1992]. Heated palm oil increased blood pressure with necrosis of cardiac tissue while fresh palm oil did not show these deleterious effects in Sprague Dawley rats [Leong et al., 2008]. Hence, fresh palm oil, with a low oxidation value, appeared to be less injurious to liver than ther- mally oxidized palm oil. According to our results, fresh palm oil treatment for 36 weeks led to some pyknosis and karyorrhexis in hepatic tissues while reused palm oil induced more severity including fat accumulation in the hepatic tissues. Our previous study reported fat accumulation in the livers of mice after 8 weeks of a combination of high fat (containing transfats) and high fructose diet [Jearapong et al., 2015]. In this study, the administration of reused palm oil for 36 weeks induced fat accumulation in the liver tissues itself but the fresh palm oil did not produce a significant change in fat accumulation. From Table 1, several unsaturated fatty acids, particularly trans-fatty acid, that were not detectable in the fresh oil, were found in the reused palm oil. These unsaturated fatty acids may derive from the deep frying of food products. For example, elaidic was from deep fried food, e.g. French fried [Bansal et al., 2009], whereas linoleic acid, eicosapentaenoic acid, and docosadienoic acid were from seafood, fish, pork, and meat [Chin et al., 1992; Hornstein et al., 1961; Hu et al., 2002]. Moreover, re-heating of palm oil with food or meats might increase accumulation of trans-fatty acid and other fatty acids in reused palm oil. In this study, mice received reused palm oil at the dose of $4.5 \mathrm{~g} / \mathrm{kg} /$ day which is equivalent to trans-fatty acid intake of $17 \mathrm{mg} / \mathrm{kg} /$ day. Dhibi et al. [2011] demonstrated that Wistar rats which received oxidized soybean oil diet (contained trans-fatty acid 123-172 mg/kg/day) and margarine diet (contained trans-fatty acid 240-336 mg/ $\mathrm{kg} /$ day) for 4 weeks showed hepatic oxidative stress with an increase in AST, ALT, ALP, and LDH levels [Dhibi et al.,

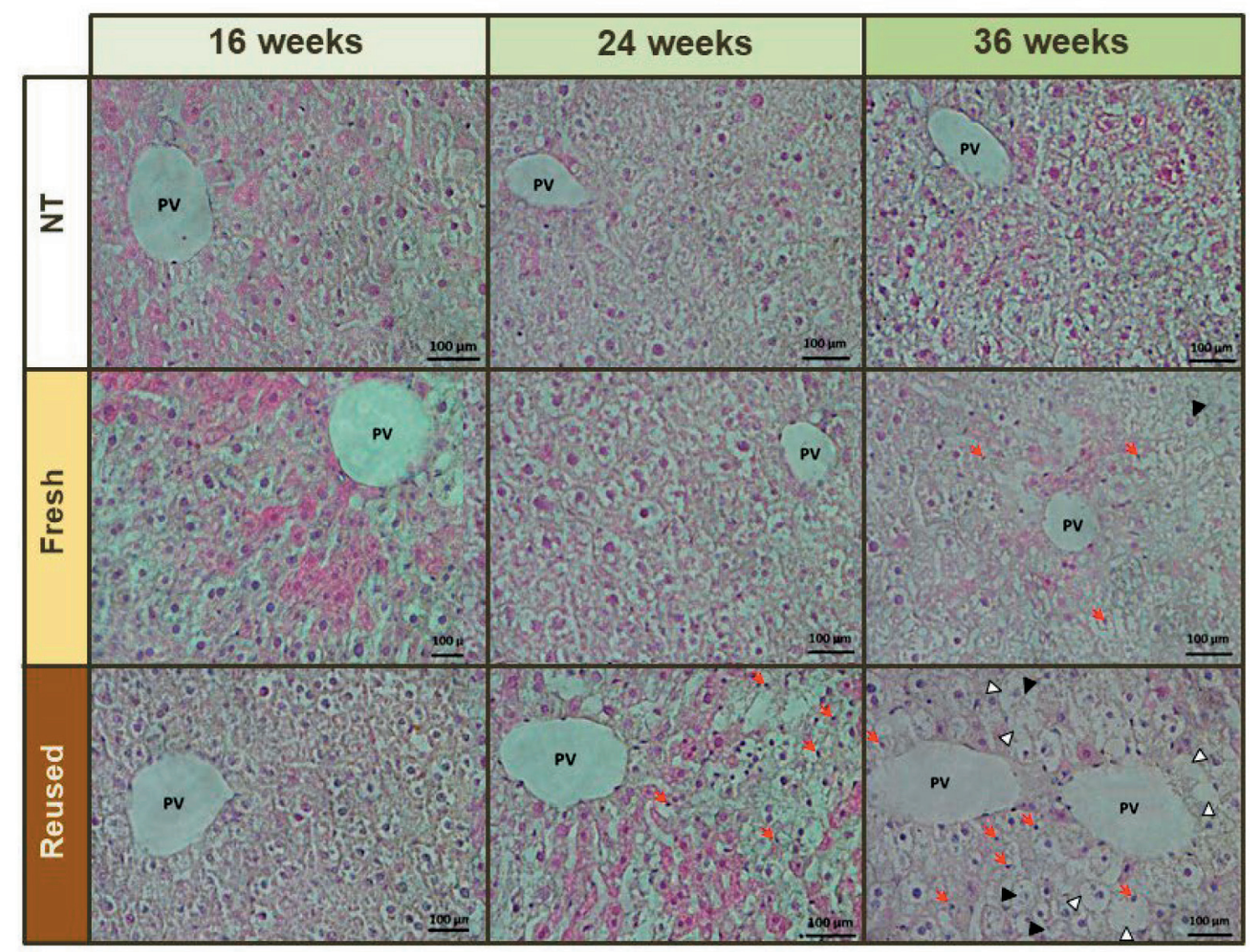

FIGURE 1. Hepatic histological changes in mice treated with fresh and reused palm oil.

Mice were orally given distilled water (NT), fresh or reused palm oil (4.5 g/kg/day) daily for 16, 24, and 36 weeks. Micrographs are shown at 400× magnification. PV, portal vein. Red arrows indicate pyknosis; black triangles indicate karyorrhexis; blank triangles indicate fat accumulation. 
2011]. Therefore, trans-fat from the re-heating process might be an important factor for hepatic fat accumulation.

\section{Effect of reused oil on oxidant-antioxidant system in the mouse livers}

Total glutathione content and GSH sharply decreased and GSSG relatively increased, resulting in a significant decrease in the GSH/GSSG ratio in mice fed reused oil for 36 weeks (Table 3). The depletion of GSH stores corresponded with the level of lipid peroxidation, presented as excessively raised TBARS contents in the mouse livers during the 36-week-treatment (Figure 2). By contrast, fresh oil consumption did not significantly disrupt the GSH/GSSG ratio, though the TBARS level was augmented at 16 weeks of the treatment. These observations revealed that both the fresh and reused palm oil induced hepatic tissue damage, but that the fresh palm oil had a less deleterious effect than the reused palm oil.

The lipid peroxidation that occurs in high-fat diets results in the production of several aldehyde species. MDA is one of several low-molecular-weight end-products formed via the decomposition of certain primary and secondary lipid peroxidation products, and is used as a convenient biomarker of lipid peroxidation because its reaction with thiobarbituric acid generates an intensely colored and readily detectable chromogen [Janero, 1990]. Wistar rats receiving hydrogenated oil containing palm oil or pure palm olein oil for 4 weeks have been shown to have significantly higher serum TBARS levels [Amini et al., 2017], which agrees with our results that both fresh and reused palm oil elevated hepatic TBARS levels. These observations reveal that both fresh and reused palm oil induce hepatic tissue damage, with the fresh palm oil having a less deleterious effect than the reused palm oil.

Another active biochemical mediator from lipid peroxidation is trans-4-hydroxy-2-hexenal (HHE), a major $\alpha, \beta$ -unsaturated aldehyde product of $n-3$ poly-unsaturated fatty acid oxidation. HHE and other products of lipid peroxidation have been shown to deplete GSH content by binding to

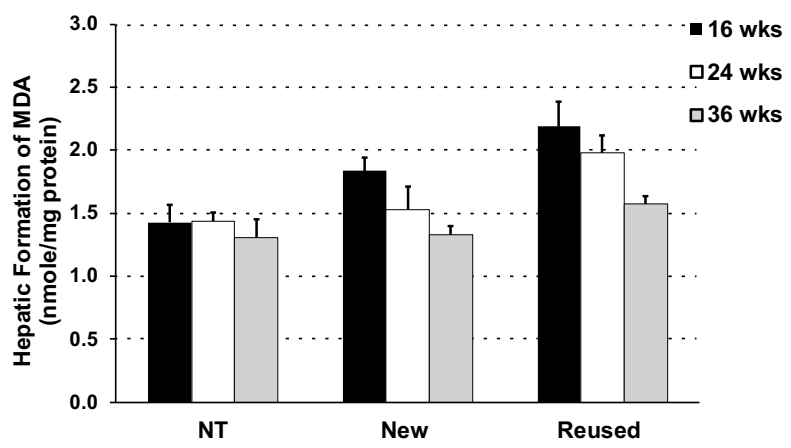

FIGURE 2. Effects of fresh and reused palm oil on the level of thiobarbituric acid reactive substances (TBARS) in mouse livers.

Mice were orally administered fresh or reused palm oil $(4.5 \mathrm{~g} / \mathrm{kg} / \mathrm{day})$ daily for 16 (black bar), 24 (blank bar), and 36 (grey bar) weeks. The control (NT) was given distilled water $(0.2 \mathrm{~mL} / \mathrm{mouse} /$ day $)$ daily for the same period. The data are expressed as the mean $\pm \mathrm{SD}(\mathrm{n}=5)$. ${ }^{*} P<0.05$ versus NT.

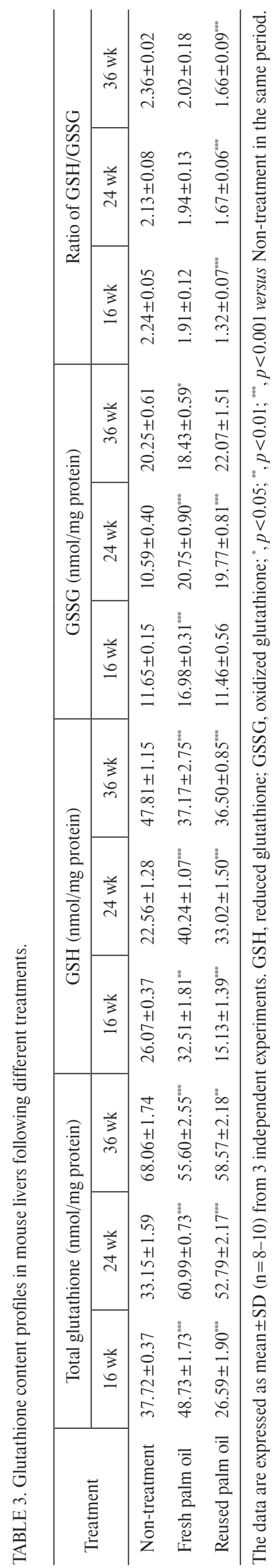


complexes with GSH via the glutathione-S-transferase reaction [Long \& Picklo, 2010]. According to our results, TBARS levels were elevated in the reused palm oil-treated mice with a decrease in the antioxidant glutathione capability detected by a lowering of the GSH/GSSG ratio.

A recent study described diet-induced nonalcoholic steatohepatitis (NASH) in $\mathrm{C} 57 \mathrm{BL} / 6 \mathrm{~J}$ mice using a diet-rich in trans-fat (40\%) and fructose (22\%) for 26 weeks [Kristiansen et al., 2016]. Pathogenesis of NASH begins with fat accumulation in hepatocytes, while oxidative stress, apoptosis, or mitochondrial dysfunction cause consequent development of inflammation and fibrosis [Day \& James, 1998]. Although our study did not investigate inflammation and fibrosis, the fat accumulation and oxidative stress via an increase in the TBARS level and a depletion of the GSH stores might imply that the ingestion of reused palm oil over a long period leads to harmful effects in the liver.

\section{Effect of reused oil on hepatic cytochrome $\mathbf{P 4 5 0}$ profiles in mice}

The expression of Cypla 2 mRNA was not modified by either fresh or reused oil (Figure 3A), whereas both fresh and reused oil significantly lessened the expression of Cyp2c29 (Figure 3B), Cyp3al1 (Figure 3D), and Cyp3a13 (Figure 3E) mRNAs. $C y$ p2el mRNA expression (Figure 3C) was significantly induced by the reused oil, but remained almost unchanged in the control mice and mice consuming fresh oil. In accordance with expectations, both fresh and reused oil significantly elevated the expression of Cyp4al0 (Figure 4A) and Cyp4a14 (Figure 4B), isoforms responsible for lipid metabolism.

An increasing number of reports documenting the adverse effects associated with food-drug interactions have been noted. Measurement of CYP activities, including those of the major drug metabolizing isoforms, CYP1A2, CYP2C, and CYP3A4, has been employed to evaluate the possibility of food-drug interactions [Sasaki et al., 2017]. In one study, levels of phase I enzymes and total CYPs were not significantly changed in rats fed a diet rich in red palm (E. guineensis) oil [Manorama et al., 1993]. On the other hand, rabbits fed ad libitum with a diet supplemented with $1 \%$ cholesterol for 8 weeks exhibited a decreased total P450 content with suppressive effects on several CYP isoforms [Irizar \& Ioannides, 1998]; activities of ethoxy- and methoxyresorufin $O$-dealkylation represented CYP1A [Namkung et al., 1988], benzphetamine $N$-demethylation of CYP2C [Ryan et al., 1984], $p$-nitrophenol hydroxylation of CYP2E1 [Koop \& Tierney, 1990], erythromycin- and ethylmorphine-demethylation of CYP3A [Wrighton et al., 1985], and lauric acid hydroxylation of CYP4A1 [Chaurasia et al., 1995]. Our finding that fresh and reused palm oil significantly down-regulates the expression of Cyp2c29, Cyp3a11, and Cyp3a13 mRNA, each encoding major drug metabolizing isoforms, correlates well with this previous study [Irizar \& Ioannides, 1998]. Food-drug interactions may therefore arise during palm oil consumption due to CYP modulation.

High-fat diet-fed ICR mice also show a significant increase in levels of hepatic MDA, CYP2E1 protein and mRNA according to one study [Jian et al., 2017], a finding which our results are in agreement with. Induction of Cyp2el expression in the reused palm oil-treated mice might be explained by the oxidative stress pathway. CYP2E1 is a member of the oxidoreductase cytochrome family, which is responsible for oxidizing a variety of substances including fatty acids, xenobiotics, ethanol, and most organic solvents [Caro \&
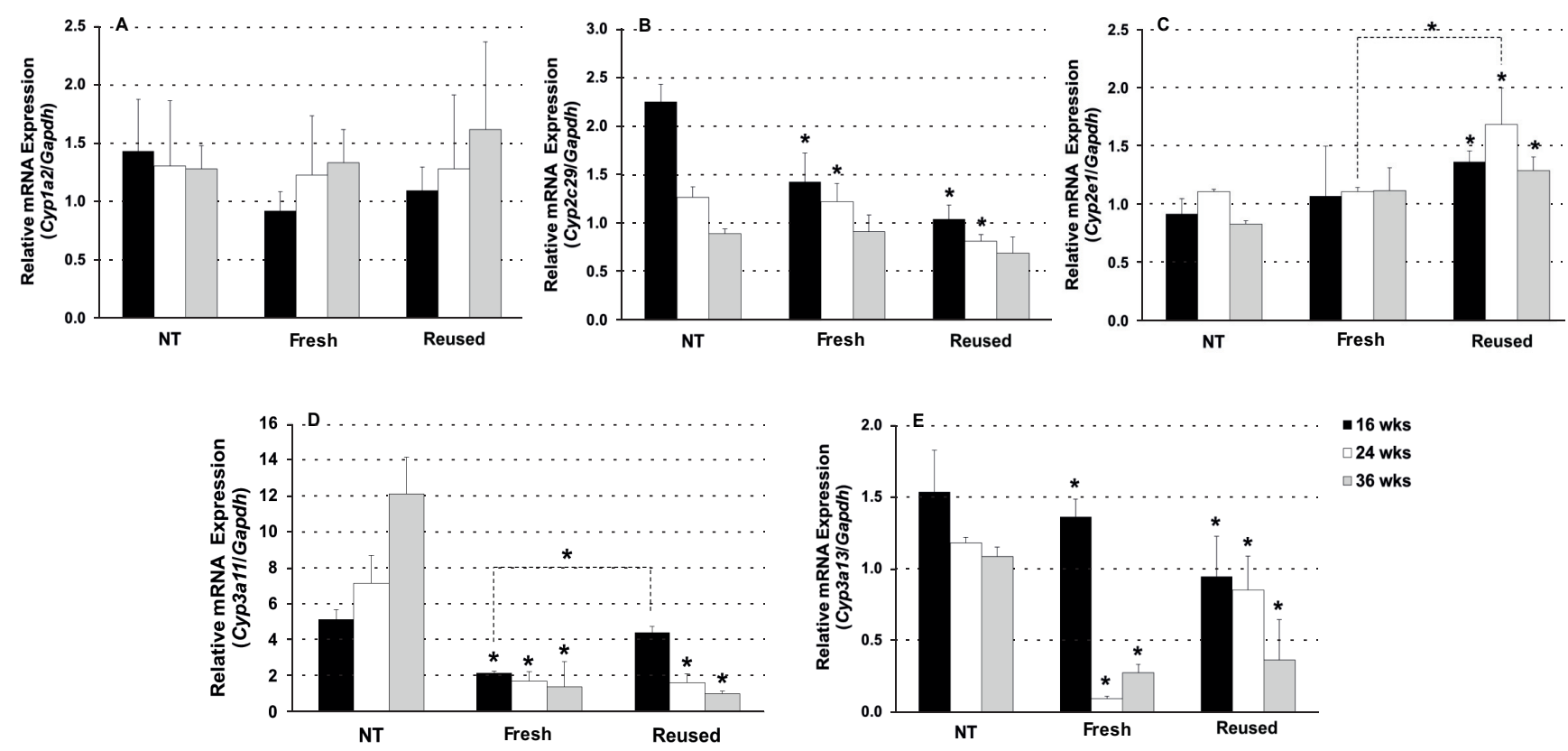

FIGURE 3. Effects of fresh and reused palm oil on the relative mRNA expression of drug metabolizing enzymes Cypla2 (A), Cyp2c29 (B), Cyp2el (C), Cyp3all (D), and Cyp3al3 (E) in mouse livers.

Mice were orally administered fresh or reused palm oil ( $4.5 \mathrm{~g} / \mathrm{kg} /$ day) daily for 16 (black bar), 24 (blank bar), and 36 (grey bar) weeks. The control (NT) was given distilled water $(0.2 \mathrm{~mL} / \mathrm{mouse} /$ day $)$ daily for the same period. The data are expressed as the meanSD $(\mathrm{n}=5) .{ }^{*} P<0.05$ versus NT. 

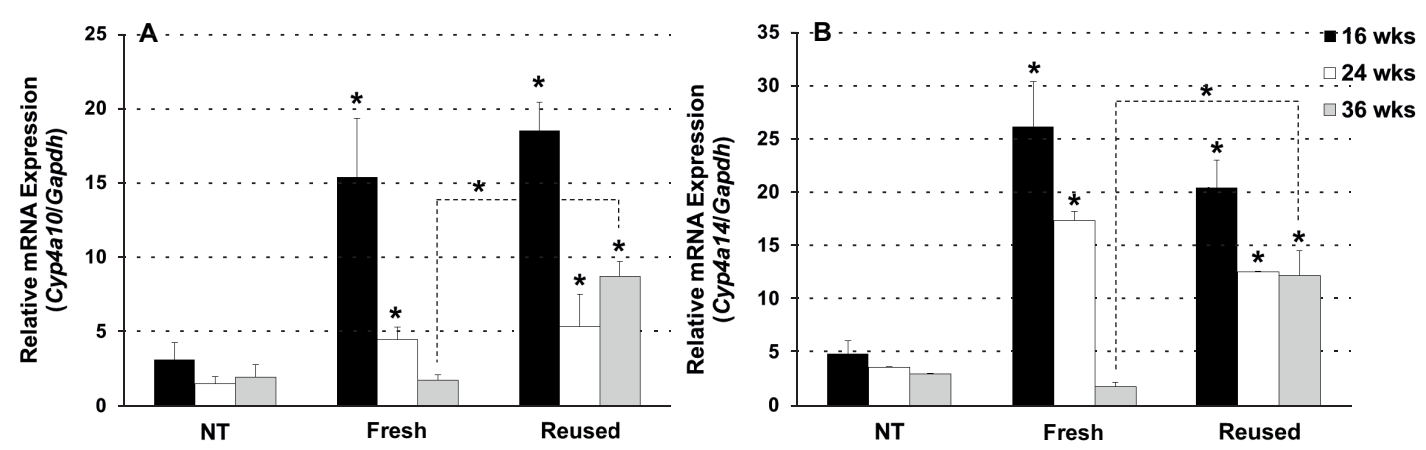

FIGURE 4. Effects of fresh and reused palm oil on the relative mRNA expression of lipid metabolizing enzymes Cyp4a10 (A) and Cyp4a14 (B) in mouse livers.

Mice were orally administered fresh or reused palm oil (4.5 g/kg/day) daily for 16 (black bar), 24 (blank bar), and 36 (grey bar) weeks. The control (NT) was given distilled water $(0.2 \mathrm{~mL} /$ mouse/day) daily for the same period. The data are expressed as the mean $\pm \mathrm{SD}(\mathrm{n}=5)$. " $P<0.05$ versus NT.

Cederbaum, 2004]. Moreover, CYP2E1 makes a significant contribution to the oxidative stress in non-alcoholic fatty liver disease (NAFLD) [Aubert et al., 2011]. The reused palm oil induced Cyp2e1 mRNA expression while the fresh one did not, confirming that the reused palm oil stimulated more hepatic oxidative stress than the fresh palm oil did via the pathway of Cyp2e1 metabolism.

In an induced steatohepatitis in mice, Cyp4a10 and $C y$ p4a14 are up-regulated and have been shown to be highly capable lipid peroxides [Leclercq et al., 2000]. Methionine and choline-deficient dietary-induced steatohepatitis in C57BL/6 mice increased Cyp4a10 and Cyp4a14 mRNA expression 2.7-fold and produced hepatic lipoperoxides [Ip et al., 2003]. However, an increase in Cyp4a expression by fresh or reused palm oil might cause the latter effect to remove excess fatty acid as a substrate for lipid peroxidation [Ip et al., 2003]. In our study, Cyp4a10 and Cyp4al4 expression was induced by both fresh and reused palm oil, whereas Cyp2el activation was only induced by the reused palm oil. Hepatic tissue damage may therefore have occurred via the oxidative stress pathway.

\section{CONCLUSIONS}

Though fresh and reused palm oil both caused liver injury through mechanisms of oxidation and depletion of GHS stores, with alteration of major CYP isoforms, the fresh palm oil was less deleterious causing, for example, lesser damage to hepatocytes, and milder modulation of TBARS level and GSH stores, with no change in the level of Cyp2el expression. Fresh palm oil is therefore preferable to reused oil, though care should be taken to limit its intake in terms of quantity, frequency, and duration of consumption.

\section{RESEARCH FUNDING}

This work was supported by the Research Group for Pharmaceutical Activities of Natural Products using Pharmaceutical Biotechnology, Khon Kaen University, Thailand under the Grant PANPB2558. We thank Dr. Tim Cushnie, Mahasarakham Univerisity, Thailand, for English-editing assistance.

\section{CONFLICT OF INTEREST}

The authors declare no conflict of interest.

\section{REFERENCES}

1. Akerboom, T.P., Sies, H. (1981). Assay of glutathione, glutathione disulfide, and glutathione mixed disulfides in biological samples. Methods in Enzymology, 77, 373-382.

2. Amini, S.A., Ghatreh-Samani, K., Habibi-Kohi, A., Jafari, L. (2017). Comparison of pure palm olein oil, hydrogenated oil-containing palm, and canola on serum lipids and lipid oxidation rate in rats fed with these oils. Archives of Iranian Medicine, 20(2), 96-100.

3. AOAC. Official Methods of Analysis of AOAC International, 20th Edition (2016a) 948.15 and 945.16

4. AOAC. Official Methods of Analysis of AOAC International, 20th Edition (2016b) 963.22 and 969.33

5. Aubert, J., Begriche, K., Knockaert, L., Robin, M.A., Fromenty, B. (2011). Increased expression of cytochrome P450 2E1 in nonalcoholic fatty liver disease: Mechanisms and pathophysiological role. Clinics and Research in Hepatology and Gastroenterology, 35(10), 630-637.

6. Bansal, G., Zhou, W., Tan, T.W., Neo, F.L., Lo, H.L. (2009). Analysis of trans fatty acids in deep frying oils by three different approaches. Food Chemistry, 116(2), 535-541.

7. Bordin, K., Kunitake, M.T., Aracava, K.K., Trindade, C.S.F. (2013). Changes in food caused by deep fat frying-a review. Archivos Latinoamericanos de Nutricion, 63(1), 5-13.

8. Bradford, M.M. (1976). A rapid and sensitive method for the quantitation of microgram quantities of protein utilizing the principle of protein-dye binding. Analytical Biochemistry, 72(1-2), 248-254.

9. Caro, A.A., Cederbaum, A.I. (2004). Oxidative stress, toxicology, and pharmacology of CYP2E1. Annual Review of Pharmacology and Toxicology, 44(1), 27-42.

10. Carter, C., Finley, W., Fry, J., Jackson, D., Willis, L. (2007). Palm oil markets and future supply. European Journal of Lipid Science and Technology, 109(4), 307-314.

11. Chao, P.M., Chao, C.Y., Lin, F.J., Huang, C. (2001). Oxidized frying oil up-regulates hepatic acyl-coa oxidase and cytochrome P-450 4 Al genes in rats and activates PPAR $\alpha$. The Journal of Nutrition, 131(12), 3166-3174. 
12. Chao, P.M., Huang, H.L., Liao, C.H., Huang, S.T., Huang, C. (2007). A high oxidised frying oil content diet is less adipogenic, but induces glucose intolerance in rodents. British Journal of $\mathrm{Nu}$ trition, 98(1), 63-71.

13. Chaurasia, C.S., Alterman, M.A., Lu, P., Hanzlik, R.P. (1995). Biochemical characterization of lauric acid $\omega$-hydroxylation by a CYP4A1/NADPH-cytochrome P450 reductase fusion protein. Archives of Biochemistry and Biophysics, 317(1), 161-169.

14. Chin, S.F., Liu, W., Storkson, J.M., Ha, Y.L., Pariza, M.W. (1992). Dietary sources of conjugated dienoic isomers of linoleic acid, a newly recognized class of anticarcinogens. Journal of Food Composition and Analysis, 5(3), 185-197.

15. Coyle, C.H., Martinez, L.J., Coleman, M.C., Spitz, D.R., Weintraub, N.L., Kader, K.N. (2006). Mechanisms of $\mathrm{H}_{2} \mathrm{O}_{2}$-induced oxidative stress in endothelial cells. Free Radical Biology \& Medicine, 40(12), 2206-2213.

16. Day, C.P., James, O.F.W. (1998). Steatohepatitis: A tale of two "hits"? Gastroenterology, 114(4), 842-845.

17. Dhibi, M., Brahmi, F., Mnari, A., Houas, Z., Chargui, I., Bchir, L., Hammami, M. (2011). The intake of high fat diet with different trans fatty acid levels differentially induces oxidative stress and non alcoholic fatty liver disease (NAFLD) in rats. Nutrition \& Metabolism, 8(1), art.no. 65.

18. Faul, F., Erdfelder, E., Lang, A.G., Buchner, A. (2007). G*Power 3: A flexible statistical power analysis program for the social, behavioral, and biomedical sciences. Behavior Research Methods, 39(2), 175-191.

19. Frankel, E.N. (2014). Research methods in lipid peroxidation In E.N. Frankel (ed). Lipid Oxidation. $2^{\text {nd }}$ edition, Elsevier Science. s pp. 129-164.

20. Hashem, A.M., Salama, E.N. (2012). The ameliorative effect of olive oil against the histopathological lesion of the liver of mice fed on repeatedly heated fried oil. The Egyptian Journal of Experimental Biology (Zoology), 8(1), 105-111, art.code 14.01.12.

21. Hornstein, I., Crowe, P., Heimberg, M. (1961). Fatty acid composition of meat tissue lipids. Journal of Food Science, 26(6), $581-586$.

22. Hu, F., Bronner, L., Al, E. (2002). Fish and omega-3 fatty acid intake and risk of coronary heart disease in women. JAMA - Journal of the American Medical Association, 287(14), 1815-1821. Retrieved from http://dx.doi.org/10.1001/jama.287.14.1815

23. Huang, W.C., Kang, Z.C., Li, Y.J., Shaw, H.M. (2009). Effects of oxidized frying oil on proteins related to alpha-tocopherol metabolism in rat liver. Journal of Clinical Biochemistry and Nutrition, 45(1), 20-28.

24. Ip, E., Farrell, G.C., Robertson, G., Hall, P., Kirsch, R., Leclercq, I. (2003). Central role of PPAR $\alpha$-dependent hepatic lipid turnover in dietary steatohepatitis in mice. Hepatology, 38(1), 123 -132 .

25. Irizar, A., Ioannides, C. (1998). Marked inhibition of hepatic cytochrome $\mathrm{P} 450$ activity in cholesterol-induced atherosclerosis in rabbits. Toxicology, 126(3), 179-193.

26. Jaarin, K., Mustafa, M. R., Leong, X.F. (2011). The effects of heated vegetable oils on blood pressure in rats. Clinics, 66(12), 2125-2132.

27. Janero, D.R. (1990). Malondialdehyde and thiobarbituric acidreactivity as diagnostic indices of lipid peroxidation and peroxidative tissue injury. Free Radical Biology and Medicine, 9(6), $515-540$.
28. Jearapong, N., Chatuphonprasert, W., Jarukamjorn, K. (2015). Effect of tetrahydrocurcumin on the profiles of drug-metabolizing enzymes induced by a high fat and high fructose diet in mice. Chemico-Biological Interactions, 239, 67-75.

29. Jian, T., Ao, X., Wu, Y., Lv, H., Ma, L., Zhao, L., Li, W. (2017). Total sesquiterpene glycosides from Loquat (Eriobotrya japonica) leaf alleviate high-fat diet induced non-alcoholic fatty liver disease through cytochrome P450 2E1 inhibition. Biomedicine \& Pharmacotherapy, 91 (Supplement C), 229-237.

30. Kemény, Z., Recseg, K., Hénon, G., Kővári, K., Zwobada, F. (2001). Deodorization of vegetable oils: Prediction of trans polyunsaturated fatty acid content. Journal of the American Oil Chemists' Society, 78(9), 973-979.

31. Koop, D.R., Tierney, D.J. (1990). Multiple mechanisms in the regulation of ethanol-inducible cytochrome P450IIE1. BioEssays, 12(9), 429-435.

32. Kristiansen, M.N.B., Veidal, S.S., Rigbolt, K.T.G., Tølbøl, K.S., Roth, J.D., Jelsing, J., Feigh, M. (2016). Obese diet-induced mouse models of nonalcoholic steatohepatitis-tracking disease by liver biopsy. World Journal of Hepatology, 8(16), 673-684.

33. Ku, S.K., Muhamad Ruhaifi, M.S., Fatin, S.S., Saffana, M., Taty Anna, K., Das, S., Kamsiah, J. (2014). The harmful effects of consumption of repeatedly heated edible oils: a short review. La Clinica Terapeutica, 165(4), 217-221.

34. Latha, R.B., Nasirullah, D.R. (2014). Physico-chemical changes in rice bran oil during heating at frying temperature. Journal of Food Science and Technology - Mysore, 51 (2), 335-340.

35. Leclercq, I.A., Farrell, G.C., Field, J., Bell, D.R., Gonzalez, F.J., Robertson, G.R. (2000). CYP2E1 and CYP4A as microsomal catalysts of lipid peroxides in murine nonalcoholic steatohepatitis. Journal of Clinical Investigation, 105(8), 1067-1075.

36. 34 Leong, X.F., Salimon, J., Mustafa, M. R., Jaarin, K. (2012). Effect of repeatedly heated palm olein on blood pressure-regulating enzymes activity and lipid peroxidation in rats. Malaysian Journal of Medical Sciences, 19(1), 20-29.

37. Leong, X.F., Aishah, A., Nor Aini, U., Das, S., Jaarin, K. (2008). Heated palm oil causes rise in blood pressure and cardiac changes in heart muscle in experimental rats. Archives of Medical Research, 39(6), 567-572.

38. Long, E.K., Picklo, M.J. (2010). Trans-4-hydroxy-2-hexenal, a product of $n-3$ fatty acid peroxidation: Make some room HNE. Free Radical Biology and Medicine, 49(1), 1-8.

39. Manorama, R., Chinnasamy, N., Rukmini, C. (1993). Effect of red palm oil on some hepatic drug-metabolizing enzymes in rats. Food and Chemical Toxicology, 31 (8), 583-588.

40. Namkung, M.J., Yang, H.L., Hulla, J.E., Juchau, M.R. (1988). On the substrate specificity of cytochrome P450IIIA1. Molecular Pharmacology, 34(5), 628-637.

41. Nebert, D.W., Wikvall, K., Miller, W.L. (2013). Human cytochromes P450 in health and disease. Philosophical Transactions of the Royal Society of London B: Biological Sciences, 368(1612), SI, art.no. 20120431. https://doi.org/10.1098/rstb.2012.0431

42. Ng, C.Y., Leong, X.F., Masbah, N., Adam, S.K., Kamisah, Y., Jaarin, K. (2014). Heated vegetable oils and cardiovascular disease risk factors. Vascular Pharmacology, 61 (1), 1-9.

43. Owu, D.U., Osim, E.E., Ebong, P.E. (1998). Serum liver enzymes profile of Wistar rats following chronic consumption of fresh or oxidized palm oil diets. Acta Tropica, 69(1), 65-73. 
44. Ryan, D.E., Iida, S., Wood, A.W., Thomas, P.E., Lieber, C.S., Levin, W. (1984). Characterization of three highly purified cytochromes P-450 from hepatic microsomes of adult male rats. Journal of Biological Chemistry, 259(2), 1239-1250.

45. Sasaki, T., Sato, Y., Kumagai, T., Yoshinari, K., Nagata, K. (2017). Effect of health foods on cytochrome P450-mediated drug metabolism. Journal of Pharmaceutical Health Care and Sciences, 3(1), 14, art.no. UNSP 14. https://doi.org/10.1186/ s40780-017-0083-x

46. Shibayama, Y. (1992). Hepatotoxicity of heated and oxygenated corn oil. Experimental and Toxicologic Pathology, 44(5), 255-258.

47. Totani, N., Ojiri, Y. (2007). Thermal deterioration of oil and frying food stuffs. Journal of Oleo Science, 56(10), 543-551.
48. Wasowicz, W., Nève, J., Peretz, A. (1993). Optimized steps in fluorometric determination of thiobarbituric acid-reactive substances in serum: importance of extraction $\mathrm{pH}$ and influence of sample preservation and storage. Clinical Chemistry, 39(12), 2522-2526.

49. Wrighton, S.A., Maurel, P., Schuetz, E.G., Watkins, P.B., Young, B., Guzelian, P.S. (1985). Identification of the cytochrome P-450 induced by macrolide antibiotics in rat liver as the glucocorticoid responsive cytochrome P-450p. Biochemistry, 24(9), 2171-2178.

Submitted: 21 August 2018. Revised: 15 October and 5 December 2018. Accepted: 13 December 2018. Published on-line: 22 January 2019. 
